\title{
An oviraptorid preserved atop an embryo-bearing egg clutch sheds light on the reproductive biology of non-avialan theropod dinosaurs
}

Shundong Bi ${ }^{1,2, *}$, Romain Amiot ${ }^{3}$, Claire Peyre de Fabrègues ${ }^{1}$, Michael Pittman ${ }^{4}$, Matthew C. Lamanna $^{5}$, Yilun $\mathrm{Yu}^{6}$, Congyu Yu ${ }^{7}$, Tzuruei Yang ${ }^{8,9}$, Shukang Zhang ${ }^{8,9}$, Qi Zhao ${ }^{8,9}$, Xing Xu ${ }^{8,9, *}$

${ }^{1}$ Centre for Vertebrate Evolutionary Biology, Institute of Palaeontology, Yunnan University, Kunming 650091, China.

${ }^{2}$ Department of Biology, Indiana University of Pennsylvania, Indiana, Pennsylvania 15705, USA.

${ }^{3}$ Univ Lyon, Univ Lyon 1, ENSL, CNRS, LGL-TPE, F-69622, Villeurbanne, France.

${ }^{4}$ Department of Earth Sciences, University of Hong Kong, Pokfulam, Hong Kong, China.

${ }^{5}$ Section of Vertebrate Paleontology, Carnegie Museum of Natural History, Pittsburgh, Pennsylvania 15213, USA.

${ }^{6}$ Yuan Pei College, Peking University, Beijing 100871, China.

${ }^{7}$ Division of Paleontology, American Museum of Natural History, New York 10024, USA.

${ }^{8}$ Key Laboratory of Vertebrate Evolution and Human Origins, Institute of Vertebrate Paleontology and Paleoanthropology, Chinese Academy of Sciences, Beijing 100044, China.

${ }^{9} \mathrm{CAS}$ Center for Excellence in Life and Paleoenvironment, Beijing 100044, China.

*Corresponding authors: X.X. (u.xing@ivpp.ac.cn or S.B. (hundong.bi@iup.edu). 


\begin{abstract}
Recent studies demonstrate that many avialan features evolved incrementally prior to the origin of the group, but the presence of some of these features, such as bird-like brooding behaviours, remains contentious, in non-avialan dinosaurs. Here we report the first non-avialan dinosaur fossil known to preserve an adult skeleton atop an egg clutch that contains embryonic remains. The preserved positional relationship of the adult to the clutch, coupled with the advanced growth stages of the embryos and their high estimated incubation temperatures, provides strong support for the brooding hypothesis. Furthermore, embryos in the clutch are at different developmental stages, suggesting the presence of asynchronous hatching - a derived feature even among crowngroup birds - in non-avialan theropods. These findings demonstrate that the evolution of reproductive biology along bird-line archosaurs was a complex rather than a linear and incremental process, and suggest that some aspects of non-avialan theropod reproduction were unique to these dinosaurs.
\end{abstract}

\title{
Keywords \\ Oviraptorosauria; Cretaceous; Clutch; Brooding; Embryos; Asynchronous hatching
}

\section{Introduction}

The reproductive biology of modern birds differs significantly from that of other extant vertebrates, and how it evolved has attracted much attention [1-5]. A key discovery pertaining to the evolution of modern avian reproductive biology is bird-like brooding behaviour in nonavialan dinosaurs, which has been indicated by multiple specimens of oviraptorosaurian skeletons preserved atop egg clutches recovered from the Upper Cretaceous of China and Mongolia [6-12]. The brooding interpretation for these associated adult and clutch specimens represents the prevailing hypothesis [7], but other viable interpretations also exist, including those that the parent perished in the act of either laying or guarding its eggs [5,13-14]. In particular, no nesting oviraptorosaur specimen has yet provided evidence that would unequivocally reject the perishing while egg laying eggs hypothesis. Furthermore, several aspects of associated adult/clutch specimens are more consistent with the perishing whileegg laying eggs than with the brooding hypothesis, namely that (1) there are significant differences in clutch size (from 6 to 22 eggs) among the specimens, suggesting that they correspond to different stages of nest construction; (2) 
the eggs are partially buried and exhibit only limited contact with the adult; and (3) no embryonic remains have been found within the eggs [13]. Here we describe a new specimen recovered from the Upper Cretaceous (Maastrichtian) Nanxiong Formation of Ganzhou, China that not only reinforces the brooding hypothesis for oviraptorosaurs but also provides significant new information on the reproductive biology of these and potentially other non-avialan theropods.

\section{Materials and Methods}

Material. Specimen LDNHMF2008 (housed at the Lande Museum of Natural History, Tangshan, Hebei Province, China) is a partially articulated partial skeleton of a medium-sized oviraptorid theropod that is missing the skull, part of the cervical series, much of the dorsal and caudal series, the pectoral girdles, and most of the humeri preserved atop an undisturbed clutch of at least 24 eggs, some of which are broken, exposing embryonic bones (Fig. 1a-c). The specimen was discovered form the Upper Cretaceous (Maastrichtian) Nanxiong Formation near the Ganzhou railway station of Ganzhou city, Jiangxi Province, China.

Histological analyses. Eggshell samples were taken from eggs C2, C5, and C8, all of which were prepared as a standard petrographic thin section and studied under a polarized light microscope. A gastralium and the humerus of the adult were also sampled for the preparation of petrographic thin sections, which were studied under a polarized light microscope to investigate bone histology.

Phylogenetic analyses. We investigated the systematic position of the new specimen via two separate analyses using Tree analysis using New Technology (TNT) [15]. First, we conducted a phylogenetic analysis based on a recently published coelurosaurian theropod dataset [16] with LDNHMF2008 added, which recovered the new specimen within Oviraptorosauria and the oviraptorosaurian subclade Caenagnathoidea. Subsequently, we conducted a second phylogenetic analysis using a recently published dataset of oviraptorosaurian phylogeny [17] with LDNHMF2008 added, which placed the new specimen within Oviraptoridae.

Isotopic analyses. Phosphates from embryonic bones were prepared and analysed for their oxygen isotope compositions $\left(\delta^{18} \mathrm{O}_{\mathrm{p}}\right)$ following the procedure described by Lécuyer [18], which consists of the isolation of apatite phosphate via acid digestion and anion-exchange resin 
followed by the quantitative precipitation of silver phosphate. Oxygen from phosphate is then converted into $\mathrm{CO}$ by high temperature pyrolysis and measured using an isotope ratio mass spectrometer (see Supplementary material for details). Oxygen and carbon isotopic compositions of eggshell carbonates were measured after carbonate conversion into $\mathrm{CO}_{2}$ through acid digestion and analysis using an isotope ratio mass spectrometer (see Supplementary material).

\section{Results}

Specimen IDNHMF2008 (housed at the Eande Museum of Natural Histery, Tangshan, Hebei Provine, China) is a partially anticulated partial skeleton of a medium-sized ovimaptorid theropod that is missing the skull, part of the cervical series, much of the dorsal and eallal series, the

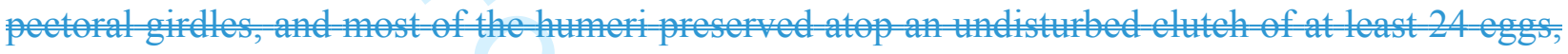
some of which are broken, exposing embryonic bones (Fig. 1).Specimen LDNHMF2008 The large skeleton-exhibits the in situ brooding posture typical of other oviraptorosaurs preserved atop egg clutches (Citipati osmolskae: IGM 100/979 [7, 10], IGM 100/1004 [8]; Nemegtomaia barsboldi: MPC-D 107/15 [12]; Oviraptoridae indet.: IVPP V9608 [9, 19]: the forelimbs are directed ventrally and posteriorly (i.e., downward and backward), covering the edges of the clutch; the hind limbs are folded such that the body of the animal is situated over the eggs and centred on the clutch; and the pelvic area is laying partly on the posterior part of the clutch and partly within its centre. As demonstrated by the location of the gastralia, which are partly exposed near the ventral midline and at a lower vertical height than the uppermost egg layerring, the body is preserved in extremely close proximity to the eggs (Fig. 1a-c).

The attending individual is presumably an adult, as indicated by the closed neurocentral sutures of all observed vertebrae. An osteohistological analysis was conducted to further determine its ontogenetic stage. Although a thin section of the left humerus indicates that its tissue has been highly modified by diagenesis, some typical osteohistological features supporting an advanced ontogenetic stage are preserved, such as abundant developed secondary osteons with different generations close to the outer circumferential layer (OCL), a transition from parallel-fibered bone tissue to lamellar bone tissue in the middle cortex, and an external fundamental system (EFS) comprising at least nine lines of arrested growth (LAGs)

$120 \mu m$ wide, compared to about 410 mbetween a LAG in the middle cortex and the innermost in the OCL (Fig. 2a). These osteohistological features suggest that LDNHMF2008 
represents a somatically mature individual. A thin section of a gastralium exhibits densely packed LAGs in the periphery of its cortex, further supporting the fully adult ontogenetic stage of LDNHMF2008 [11]. The thin sections clearly show that the humerus and gastralium lack medullary bone. Whereas the lack of medullary bone in the humerus and gastralium raises the possibility that the attending individual may have been male, a female identity also cannot be ruled out because the medullary bone is extremely rare in non-avialan dinosaurs [20] and its development is highly variable even in extant female birds [21].

The adult skeleton exhibits anatomical features typical of oviraptorosaurs in general as well as several hallmarks of less inclusive oviraptorosaurian clades. For example, the presence of pleurocoels on the caudal vertebral centra and an anteriorly concave pubic shaft indicate a position within Caenagnathoidea, and one rather than two pneumatic foramina on the lateral surfaces of the cervical centra, a pubis that is short relative to the ilium and that has a small, shoelike distal boot with the anterior process longer than the posterior process, a small groove rather than a large cleft separating the greater and lesser trochanters of the femur, and a third metatarsal that is not proximally mediolaterally compressed support oviraptorid affinities [16]. Two phylogenetic analyses using different datasets also place the new fossil within Oviraptorosauria and Caenagnathoidea; the latter analysis, specific to Oviraptorosauria, further recovers the specimen within Oviraptoridae, as a sister taxon of other late-diverging oviraptorids (Fig. 3a,b).

The clutch consists of at least 24 eggs preserved immediately beneath and in extremely close proximity to the adult skeleton with little to no intervening sedimentary matrix. The outer and inner clutch diameters are 78 and $26 \mathrm{~cm}$, respectively. The clutch is mostly intact, exhibiting almest nelittle or only slight deformation or compression of the eggs and preserving paired eggs arranged in three superposed rings unlike $\simeq 1-2$ rings in other clutches $[8-10,13]$. Like in other Asian clutches, the eggs are oriented subhorizontally and slightly tilted toward the center [7,9]. Twelve eggs are exposed in the uppermost ring (herein termed ring $\mathrm{C}$ ), nine are visible in the middle ring (B), and three are exposed in the lowermost ring (A). The eggs in the middle ring is positioned farther away from the center than those in the rings $\mathrm{A}$ and $\mathrm{C}$ so the eggs of the lower ring $\mathrm{A}$ are overlain at its base by the middle eggs, but directly by uppermost eggs above. The clutch consists of at least 24 eggs preserved immediately beneath and in extremely close proximity to the adtlt skeleton with little to no intervening sedimentary matrix. They are aligned radially and oriented subhorizontally (Fig. 1a-c;-see also 
The eggs are $\sim 215 \mathrm{~mm}$ in length and $\sim 85 \mathrm{~mm}$ in width across their equatorial regions (Supplementary table 1). The outer surface of all eggs exhibits linearituberculate ornamentation made up of fine, densely packed ridges approximately $2-3 \mathrm{~mm}$ in width, which are aligned with the long axis of the eggs in the equatorial region but are more randomly distributed at the poles. The eggshell is thin, approximately $1.08 \mathrm{~mm}$ thick without the height of the ornamentation. The eggshell exhibits a mammillary layer topped by a continuous layer and an undulant boundary between the two layers. The undulant growth lines in the continuous layer are parallel to the outer surface of the eggshell (Fig. 2b). The thickness of the mammillary and continuous layers varies from $0.19-0.31 \mathrm{~mm}$ and $0.56-0.75 \mathrm{~mm}$ (without the height of the ornamentation), respectively. The thickness ratio of the mammillary to the continuous layer varies from $0.25-0.5$. Based on the egg size, eggshell thickness and the distinct undulant boundary between the mammillary and continuous layers of eggshell, the eggs can be referred to Macroolithus yaotunensis [22].

Embryonic material is ebserved exposed in -at least seven of theseven eggs (C2-C8 and B9), but ossified bones with identifiable morphologies are observed only in eggs B9, C2, C3, and C5 and B9 (Fig. 4a-d). The skeleton within egg C2 is probably complete and many bones have been exposed, including vertebrae, dorsal ribs, a humerus, both ilia and femora, and a tibia. The skeleton is semi-articulated and exhibits a generally curled posture (Fig. 4b), as in other described oviraptorosaurian embryos such as that of Beibeilong sinensis [23]. The humerus is nearly complete and fully ossified with finished proximal and distal end. One of the exposed femora is robust and nearly complete. Both extremities of this bone are exposed and fully ossified. In egg 
C3, some vertebrae, dorsal ribs, and putative pelvic bones are exposed and localized in one corner of the egg (Fig. 4c). There are approximately as many exposed bones in egg C5 (Fig. 4d) as there are in $\mathrm{C} 2$. The femur within C5 exhibits defined articular surfaces, and its stage of ossification is similar to that seen in the very latest stages of development of crown bird and other oviraptorid embryos [24]. As eggs C2, C3, and C5 belong to the same layer and are likely to have been laid within a short time period, differences in size and developmental stages among these embryos may be a consequence of asynchronous hatching, as has been previously suggested for oviraptorids_[24, 25]. Except for egg C3, egg B9 (Fig. 4a) exhibits fewer exposed elements than eggs from the $\mathrm{C}$ layer. Approximately 12 bones are distinctly visible compared with more than 20 in eggs C2 and C5. Most of the bones in egg B9 cannot be identified. Nevertheless, two long bones that we identify as femora due to their length, robustness, and curvature have poorly defined extremities; i.e., their epiphyses are not completely ossified. Given the degrees of ossification, the embryos in egg B9 areis developmentally earlier than those in eggs C2 and C5. The limb bones preserved within different eggs differ in length; for example, the femur in egg C5 is $5.5 \mathrm{~cm}$ long whereas the femur in B9 is $4 \mathrm{~cm}$ long. In sum, their differing limb lengths and degrees of ossification suggest that the embryos in eggs from the middle layer (B) are developmentally earlier than those in eggs from the upper layer (C). In general, developmental variation is seen not only between eggs from different rings, but also from the same ring, and a complete reconstruction of the developmental variation pattern from LDNHMF2008 is currently not possible.

To estimate the temperature at which the embryos mineralized their skeletons, we measured and analyzed the stable oxygen isotopic compositions of the embryonic bone apatite phosphate $\left(\delta 18 \mathrm{O}_{\mathrm{p}}\right)$ and the eggshell carbonate $\left(\delta 18 \mathrm{O}_{\mathrm{c}}\right)$ of eggs $\mathrm{C} 2, \mathrm{C} 3$, and $\mathrm{C} 8$. The calculation of incubation temperature is based on the following considerations: (1) the eggshell $\delta 18 \mathrm{O}_{\mathrm{c}}$ value reflects the oxygen isotopic composition of body fluids of the egg-laying female from which eggshell precipitated. Because the water of egg fluids originates from the egg-laying female body water and is transmitted without isotopic fractionation, eggshell $\delta 18 \mathrm{O}_{\mathrm{c}}$ values also indirectly reflect the oxygen isotope composition of egg fluids; and (2) the embryonic bones precipitated from these egg fluids with a phosphate-water oxygen isotope fractionation that was controlled by egg temperature [26]. An updated version of the time-dependent model of Amiot et al. [26] that predicts the $\delta 18 \mathrm{O}_{\mathrm{p}}$ evolution of the embryonic skeleton during incubation as a function of egg 
temperature was used, and measured eggshell $\delta 18 \mathrm{O}_{\mathrm{c}}$ and embryonic bone $\delta 18 \mathrm{O}_{\mathrm{p}}$ values were used as boundary conditions (see Supplementary material for model description and outputs). Assuming the primary preservation of both eggshell carbonate and bone phosphate stable isotope compositions in the three eggs and their embryos based on the good preservation of both diminutive embryo bones and eggshell calcite microstructure, the measured values best match those modelled at incubation temperatures of $36-38^{\circ} \mathrm{C}$ for $\mathrm{C} 2$ and $\mathrm{C} 3$ and $30-32^{\circ} \mathrm{C}$ for $\mathrm{C} 8$ (Fig. 5a-c). Thus, our isotopic analysis shows that temperature differences existed among the eggs, at least within the layer-ring C. Given that non-avialan theropod dinosaurs had elevated body temperatures within the $33^{\circ} \mathrm{C}-38^{\circ} \mathrm{C}$ range [27]. Estimated incubation temperatures for two of the three analysed eggs are well within the expected range of brooding behaviour $\left(36-38^{\circ} \mathrm{C}\right)$, whereas the third embryo (from egg C8) seems to have been incubated at a slightly lower temperature, within the $30-32^{\circ} \mathrm{C}$ range. This lower calculated temperature might be the result of its position in the clutch at the opposite side of eggs C2 and C3; this area of the clutch might have been less covered by the adult body and therefore experienced a lower incubation temperature. It would also be consistent with the slightly earlier developmental stage of the embryo within egg C8 compared those in $\mathrm{C} 2$ or $\mathrm{C} 3$, as incubation temperature affects the speed of embryo development and the duration of incubation. It is noteworthy that $30-32^{\circ} \mathrm{C}$ is still within the viable range of brooding temperatures [28].

\section{Discussion and conclusion}

LDNHMF2008 is the first non-avialan dinosaur specimen to preserve an association of an adult atop a nest of eggs that contains embryos. Because the embryos died at late developmental stages, the adult clearly had tended the nest for an extended period and did not perish in the act of egg laying, contrary to what has previously been suggested [13]. Moreover, the estimated incubation temperature for the eggs is consistent with the body temperature of brooding birds $\left(30-38^{\circ} \mathrm{C}\right)$. In contrast, the incubation temperature for reptiles is always lower $\left(26-32^{\circ} \mathrm{C}\right)$. Taken together, the association of the close contact between the adult skeleton and the eggs, embryos in late developmental stages, and the high, oxygen isotope-based estimated incubation temperature effectively rules out both the perishing while laying eggs [13] egg laying and the reptile-like nest guarding hypotheses [5,14]. Instead, it strongly supports the brooding hypothesis for associated adult/clutch oviraptorosaurian specimens [7]. 
Previous studies demonstrate that the evolution of modern avialan reproductive biology occurred in multiple stages, with some bird reproductive features having their origins among non-avialan theropods and other features having yet to evolve even among stem birds [1]. Oviraptorosaurgrade maniraptorans represent an intermediate stage in the evolution of modern avialan reproductive biology in that they are widely considered to possess such features as iterative egg laying, possibly paternal brooding to aid incubation in a partially open nest, and synchronous hatching of eggs via delayed incubation [1]. The discoveries reported herein support the presence of some (e.g., iterative egg laying and paternal brooding behaviour) but not all (e.g., synchronous hatching) of these features in oviraptorosaurs.

In most modernmost precocial primitive-extant birds, the embryos in a single clutch are at the same ontogenetic stage and hatch simultaneously, or nearly so [29]. Synchronous hatching is a plesiomorphic feature not only for crown-group birds, but also for most other vertebrate groups. At the same time, many altricial birds are unusual in displaying asynchronous hatching, a feature that is presumed to be derived for crown birds [29,30]. LDNHMF2008 displays developmental variation within a single brooded clutch. As noted above, the differing developmental maturity among the different egg $\underline{s}$ tembryo layers in the specimen reinforces that asynchronous hatching might have occurred among non-avialan theropods [24-25]. Although it cannot be completely excluded that the developmental failures of some eggs lead to the ontogenetic variation observed in the clutch [31], the occurrence of asynchronous hatching is further supported by the differing egg/embryo temperatures estimated for various eggs within the clutch.

\section{Due to the limited and complex data recovered from LDNHMF2008}

pattern of the embryos is not identifiable-provides additional mformation on the bropding behaviour of oviraptorosaurian theropods, and thus it is difficult to infer the cause of asynchronous hatching in this oviraptorid dinosaur.

explain the availableOur data

withsuggestive of the following hypothesis. As in ostriches, oviraptorosaurs would have started incubation of the nest only after all eggs had been laid, such that the lower eggs, which had been laid earlier, would have been incubated for proportionally the same amount oftess time laying than would the upper eggs. However, the upper eggs would have hatched earlier than the lower eggs because, being closer to the brooding adult, they would have received more heat from this individual than the lower eggs, and thus the embryos therein would have developed more 
rapidly. Although a quantitative estimation of hatching speed is not possible for this particular fossil, living birds provide some data for reference, in which the hatching spreads are variable and for Yellow Warbler 5-egg clutches, it is 2 days [32]. Also, because the brooding adult would have been in different degrees of proximity even to eggs in the same layerring, eggs from a single layer ring could also potentially have hatched at different times.

The discovery of asynchronous hatching in oviraptorosaurs is unexpected given its late appearance even among crown birds. Apparently, this feature evolved independently in some crown-group birds and at least oviraptorosaurians among non-avialan dinosaurs, reinforcing previous hypotheses that the evolution of modern avialan reproductive biology was not an incremental, linear process. Rather, the independent evolution of asynchronous hatching in a nonavialan theropod approaching the origin of birds provides another example of the prevalence of homoplasies across this major evolutionary transition. Moreover, it rejects the interpretation that non-avialan theropods were, in a behavioural sense, strictly intermediate between birds and other archosaurs, further highlighting the uniqueness of various non-avialan dinosaur subgroups. Finally, the scenario we proposed for oviraptorid hatching is not entirely consistent with data from living birds because birds normally display synchronous hatching if incubation starts after all eggs of a clutch have been laid, and this further highlights the complex behaviours of nonavialan dinosaurs as a group of animals with their own anique evolutionary history.

\section{Acknowledgments}

We thank A. McAfee and M. Ren for illustration; J. Lu for providing the specimen for research; L. Xiang for the specimen preparation; and H. Zang for photography. Support for this research is from the Double First-Class joint program of Yunnan Science \& Technology Department and Yunnan University (2018FY001-005), China-Myanmar Joint Laboratory for Ecological and Environmental Conservation, and HKU Faculty of Science RAE Improvement Fund. R.A. was supported by the CNRS program INSU INTERRVIE and X.X. by the National Natural Science Foundation of China (41688103).

\section{Conflict of interest}

The authors declare that they have no conflict of interest. 


\section{References}

[1] Varricchio DJ, Jackson FD. Reproduction in Mesozoic birds and evolution of the modern avian reproductive mode. Auk 2016; 133:654-684.

[2] Varricchio DJ, Jackson FD, Borkowski J, Horner JR. Nest and egg clutches of the dinosaur Troodon formosus and the evolution of avian reproductive traits. Nature 1997; 385:247-250.

[3] Sato T, Cheng YN, Wu X, et al. A pair of shelled eggs inside a female dinosaur. Science $2005 ; 308: 375$.

[4] Zheng X, O’Connor J, Huchzermeyer F, et al. Preservation of ovarian follicles reveals early evolution of avian reproductive behaviour. Nature 2013;495:507-511.

[5] Deeming DC. Importance and evolution of incubation in avian reproduction. In: Deeming DC, editor. Avian incubation: behaviour, environment and evolution. Oxford: Oxford University Press; 2002, p. 1-7.

[6] Osborn HF. Three new Theropoda, Protoceratops zone, central Mongolia. Am Mus Novit 1924;128:1-7.

[7] Norell MA, Clark JM, Chiappe LM, Dashzeveg D. A nesting dinosaur. Nature 1995;378:774776.

[8] Norell MA, Balanoff AM, Barta DE, Erickson GM. A second specimen of Citipati osmolskae associated with a nest of eggs from Ukhaa Tolgod, Omnogov Aimag, Mongolia. Am Mus Novit 2018;3899:1-45.

[9] Dong Z, Currie PJ. On the discovery of an oviraptorid skeleton on a nest of eggs at Bayan Mandahu, Inner Mongolia, People’s Republic of China. Can J Earth Sci 1996;33:631-636.

[10] Clark JM, Norell MA, Chiappe LM. An oviraptorid skeleton from the Late Cretaceous of Ukhaa Tolgod, Mongolia, preserved in an avianlike brooding position over an oviraptorid nest. Am Mus Novit 1999;3265:1-36. 
[11] Erickson GM, Rogers KC, Varricchio DJ, et al. Growth patterns in brooding dinosaurs reveals the timing of sexual maturity in non-avian dinosaurs and genesis of the avian condition. Biol Lett 2007;3:558-561.

[12] Fanti F, Currie PJ, Badamgarav D. New specimens of Nemegtomaia from the Baruungoyot and Nemegt formations (Late Cretaceous) of Mongolia. PLos One 2012;7:e31330.

[13] Yang TR, Wiemann J, Xu L, et al. Reconstruction of oviraptorid clutches illuminates their unique nesting biology. Acta Palaeontol Pol 2019;64:581-596.

[14] Deeming DC. The fossil record and evolution of avian egg nesting and incubation. In: Deeming DC, Reynolds SJ, editors. Nests, Eggs, and Incubation: New Ideas about Avian Reproduction. Oxford: Oxford University Press; 2015, p. 8-15.

[15] Goloboff PA, Catalano SA. TNT version 1.5, including a full implementation of phylogenetic morphometrics. Cladistics 2016;32:221-238.

[16] Brusatte SL, Lloyd GT, Wang SC, Norell MA. Gradual assembly of avian body plan culminated in rapid rates of evolution across the dinosaur-bird transition. Curr Biol 2014;24:2386-2392.

[17] Yu Y, Wang K, Chen S, et al. A new caenagnathid dinosaur from the Upper Cretaceous Wangshi Group of Shandong, China, with comments on size variation among oviraptorosaurs. Sci Rep 2018;8:5030.

[18] Lécuyer C. Oxygen isotope analysis of phosphate. In: de Groot PA, editor. Handbook of Stable Isotope Analytical Techniques. Elsevier; 2004, p. 482-496.

[19] Longrich NR, Currie PJ, Dong Z. A new oviraptorid (Dinosauria: Theropoda) from the Upper Cretaceous of Bayan Mandahu, Inner Mongolia. Palaeontology 2010;53:945-960.

[20] Jin X, Varricchio DJ, Poust AW, He T. An oviraptorosaur adult-egg association from the Cretaceous of Jiangxi Province, China. J Vertebr Paleontol 2020, e1739060. 
[21] Canoville A, Schweitzer MH, Zanno LE. Systemic distribution of medullary bone in the avian skeleton: ground truthing criteria for the identification of reproductive tissues in extinct Avemetatarsalia. BMC Evol Biol 2019;19:71.

[22] Zhao Z. The microstructure of the dinosaurian eggshells of Nanxiong, Guangdong Provinceon the classification of dinosaur eggs. Vert PalAsiat 1975;13:105-117.

[23] Pu H, Zelenitsky DK, Lü J, et al. Perinate and eggs of a giant caenagnathid dinosaur from the Late Cretaceous of central China. Nat Comm 2017;8:14952.

[24] Weishampel DB, Fastovsky DE, Watabe M, et al. New oviraptorid embryos from BuginTsav, Nemegt Formation (Upper Cretaceous), Mongolia with insights into their habitat and growth. J Vertebr Paleontol 2008;28:1110-1119.

[25] Yang TR, Engler T, Lallensack JN, et al. Hatching asynchrony in oviraptorid dinosaurs sheds light on their unique nesting biology. Integr Comp Biol 2019: obz030.

[26] Amiot R, Wang X, Wang S, et al. 8180 -derived incubation temperatures of oviraptorosaur eggs. Palaeontology 2017;60:633-647.

[27] Amiot R, Lécuyer C, Buffetaut E, et al. Oxygen isotopes from biogenic apatites suggest widespread endothermy in Cretaceous dinosaurs. Earth Planet Sci Lett 2006;246:41-54.

[28] Deeming DC, Ferguson MWJ. Egg turning during incubation has no effect upon growth of embryos of Alligator mississippiensis. Acta Zool 1991;72:125-128.

[29] Stoleson SH, Beissinger SR. Hatching asynchrony and the onset of incubation in birds, revisited: when is the critical period? Curr Ornithol 1995;13:191-270.

[30] Varricchio DJ, Horner JR, Jackson FD. Embryos and eggs for the Cretaceous theropod Troodon formosus. J Vertebr Paleontol 2002;22:564-576.

[31] Jackson FD, Varricchio DJ, Jackson RA., et al. Taphonomy of extant desert tortoise (Gopherus agassizii) and loggerhead sea turtle (Caretta caretta) nesting sites: implications for interpreting the fossil record. Palaios 2015; 30(3):207-223. 
32] Hébert PN, Sealy SG. Hatching asynchrony in Yellow Warblers: A test of the nest-failure hypothesis. Ornis Scand 1993; 24(1): 10-14.

1

2

3

4

5

6

7

8

9

10

11

12

13

14

15

16

17

18

19

20

21

22

23

24

25

26

27

28

29

30

31

32

33

34

35

36

37

38

39

40

41

42

43

44

45

46

47

48

49

50

51

52

53

54

55

56

57

58

59

60

www.scibull.com 


\section{$\underline{\text { Figure captions }}$}

Fig. 1 LDNHMF2008, an oviraptorid specimen consisting of an adult skeleton preserved atop an embryo-bearing egg clutch. (a) Photograph, (b) Interpretive drawing with bones and gastroliths in white and eggs color-coded by layer (A, red; B, green; C, blue). (c) Restoration (white indicates bones preserved in the adult skeleton). Abbreviations: I, digit I; II, digit II; III, digit III; A\#, egg in lowermost layer (A); as, astragalus; B\#, egg in middle layer (B); C\#, egg in uppermost layer (C); cav, caudal vertebra; ch, chevron; cv, cervical vertebra; di, manual digit; dr, dorsal ribs; dv, dorsal vertebra; em, egg known to preserve embryo; fe, femur; fi. fibula; ga, gastralium; gl, gastroliths; h, humerus; il, ilium; is, ischium; mt, metatarsal; $\mathrm{O}_{2}$, egg sampled for oxygen isotope analysis; pb, pubis; pp, pedal phalanges; ra, radius; sl, semilunate carpal; ti, tibia; ul, ulna. Note that $\mathrm{C} 11$ and $\mathrm{C} 12$ are not paired eggs. The eggs that would have been paired with $\mathrm{C} 11$ and $\mathrm{C} 12$ are probably not preserved, as is the case for some other eggs and skeletal elements.

Fig. 2 Bone histology and eggshell of LDNHMF2008. (a) Cross section of humerus under polarized light. The presence of an external fundamental system (EFS) consisting of nine densely packed line of arrested growth (LAGs, white arrows), the densely packed secondary osteons, and other osteohistological features indicate that the specimen represents a fully-grown adult, (b) Petrographic thin section of eggshell from egg B9. The undulant boundary between the mammillary layer (ML) and the continuous layer (CL) is indicated by a white line. The base of the ML is missing, possibly due to embryo-induced erosion.

Fig. 3 Phylogenetic position of LDNHMF2008. (a) Reduced consensus of 64 most parsimonious trees (MPTs) of 4,655 steps recovered via parsimony analysis of the data matrix presented by Brusatte et al. [16] with the addition of LDNHMF2008. Note position of specimen (in bold) within Caenagnathoidea (indicated by arrow). (B) Strict consensus of 119 MPTs of 670 steps recovered via parsimony analysis of the data matrix presented by $\mathrm{Yu}$ et al. [17] with the addition of LDNHMF2008. Note position of specimen (in bold) within Oviraptoridae, as a fairly late-branching member of this clade (indicated by arrow).

Fig. 4 Embryonic skeletons preserved in eggs B9, C2, C3, and C5 of LDNHMF2008. (a to d) Photographs and line drawings of embryonic bones in eggs B9 (a), C2 (b), C3 (c), and 
C5 (d). Abbreviations: cav, caudal vertebrae; dv, dorsal vertebrae; fe, femur; h, humerus; il, ilium; pb, pubis; ph, phalanges; ra, radius; ti, tibia; ul, ulna.

Fig. 5 Incubation temperatures of three eggs of LDNHMF2008. (a to c) Outputs of the model predicting the temporal evolution of the $\delta^{18} \mathrm{O}_{\mathrm{p}}$ value of oviraptorosaurian embryo bone phosphate as a function of embryo body temperature (black lines). Predicted embryo bone $\delta^{18} \mathrm{O}_{\mathrm{p}}$ evolution is plotted against incubation time for temperatures ranging from 30 to $40^{\circ} \mathrm{C}$ (black lines) and compared to the measured $\delta^{18} \mathrm{O}_{\mathrm{p}}$ value of the embryonic bone of unknown growth stage (dashed grey line) for eggs C2 (a), C3 (b), and C8 (c). Considering the advanced ossification of the embryonic skeletons in $\mathrm{C} 2, \mathrm{C} 3$, and $\mathrm{C} 8$, they might correspond to the final days or weeks of their incubation period where measured $\delta^{18} \mathrm{O}_{\mathrm{p}}$ values intersect the $36^{\circ} \mathrm{C}$ and $38^{\circ} \mathrm{C}$ modelled lines for $\mathrm{C} 2$, around $35^{\circ} \mathrm{C}$ to $37^{\circ} \mathrm{C}$ for $\mathrm{C} 3$, and $30^{\circ} \mathrm{C}$ to $32^{\circ} \mathrm{C}$ for $\mathrm{C} 8$.

\section{Supplementary material}

\section{Part A. Systematic paleontology and supplemental description}

Part B. Phylogenetic analysis

Part C. Isotopic analysis

Part D. Institutional abbreviations

Part E. Tables of measurements and results of isotopic analysis

Table S1. Length and width measurements of oviraptorid eggs B3, B4, C1-C3, and C12 of oviraptorid specimen LDNHMF2008.

Table S2. Selected measurements of adult oviraptorid skeleton in LDNHMF2008.

Table S3. Results of isotopic analyses.

Part F. References

Supplementary video 1. Photogrammetry video of LDNHMF2008. 


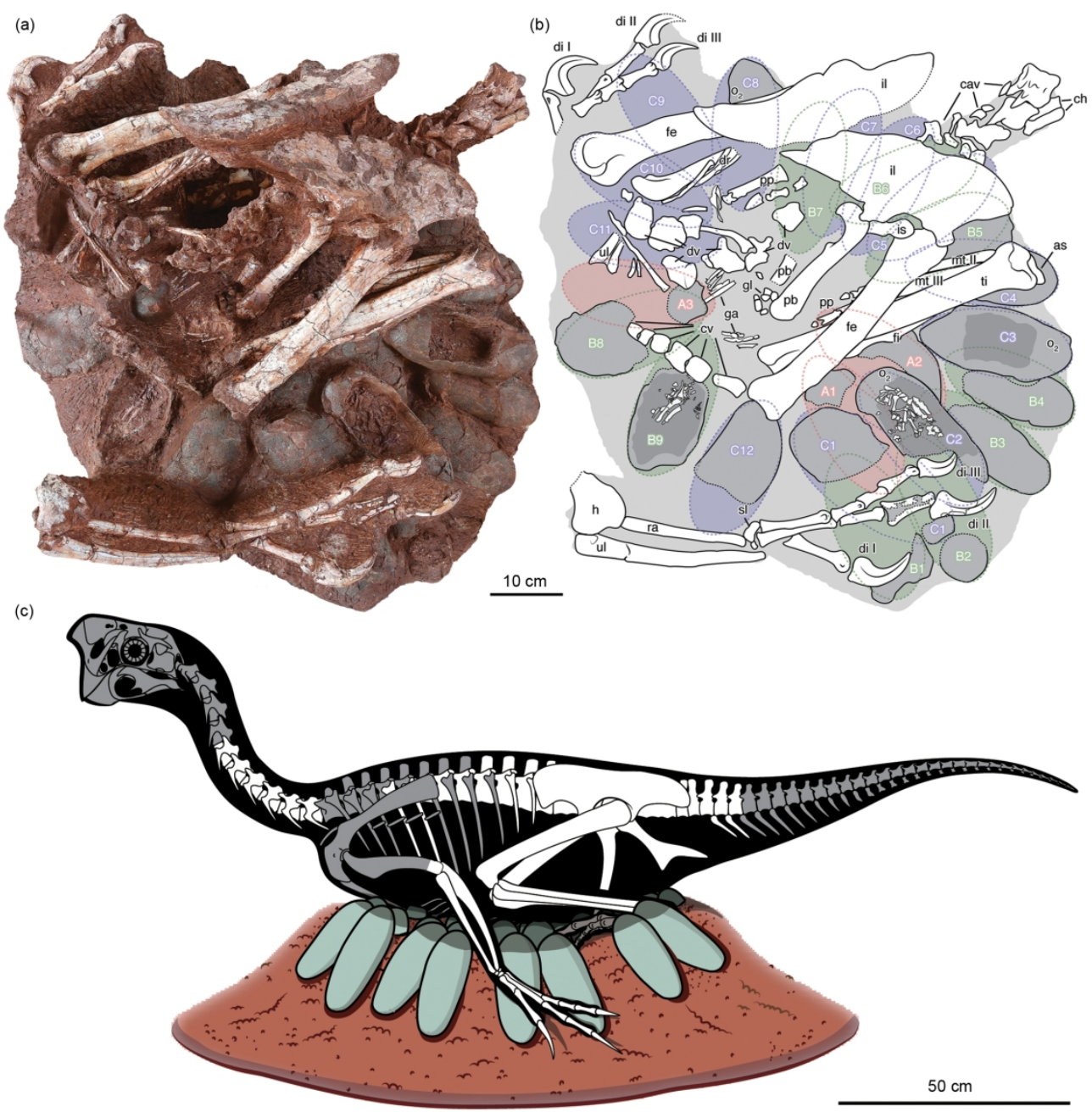

Figure 1

$189 \times 200 \mathrm{~mm}(300 \times 300$ DPI $)$ 

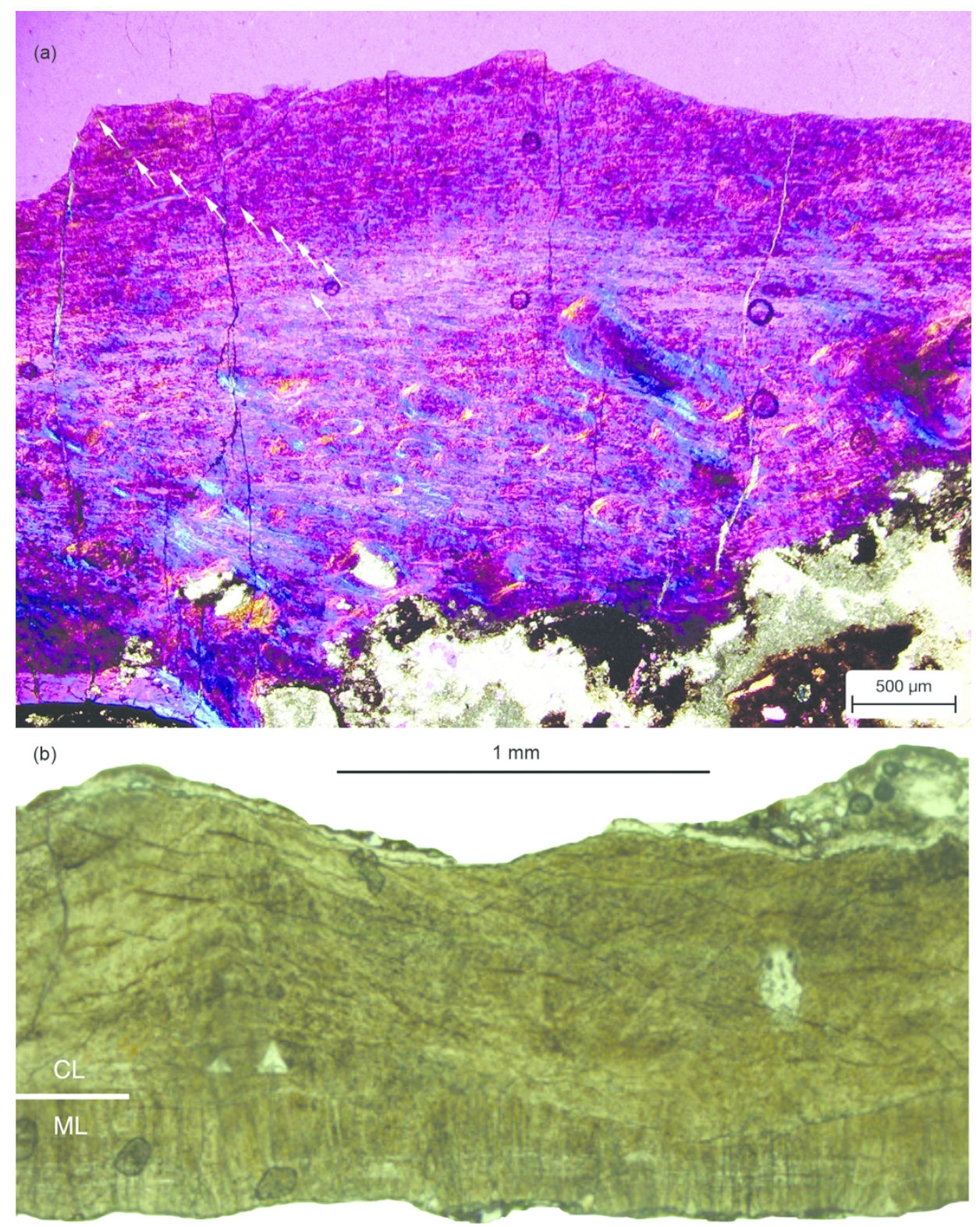

Figure 2

$140 \times 178 \mathrm{~mm}(300 \times 300 \mathrm{DPI})$ 


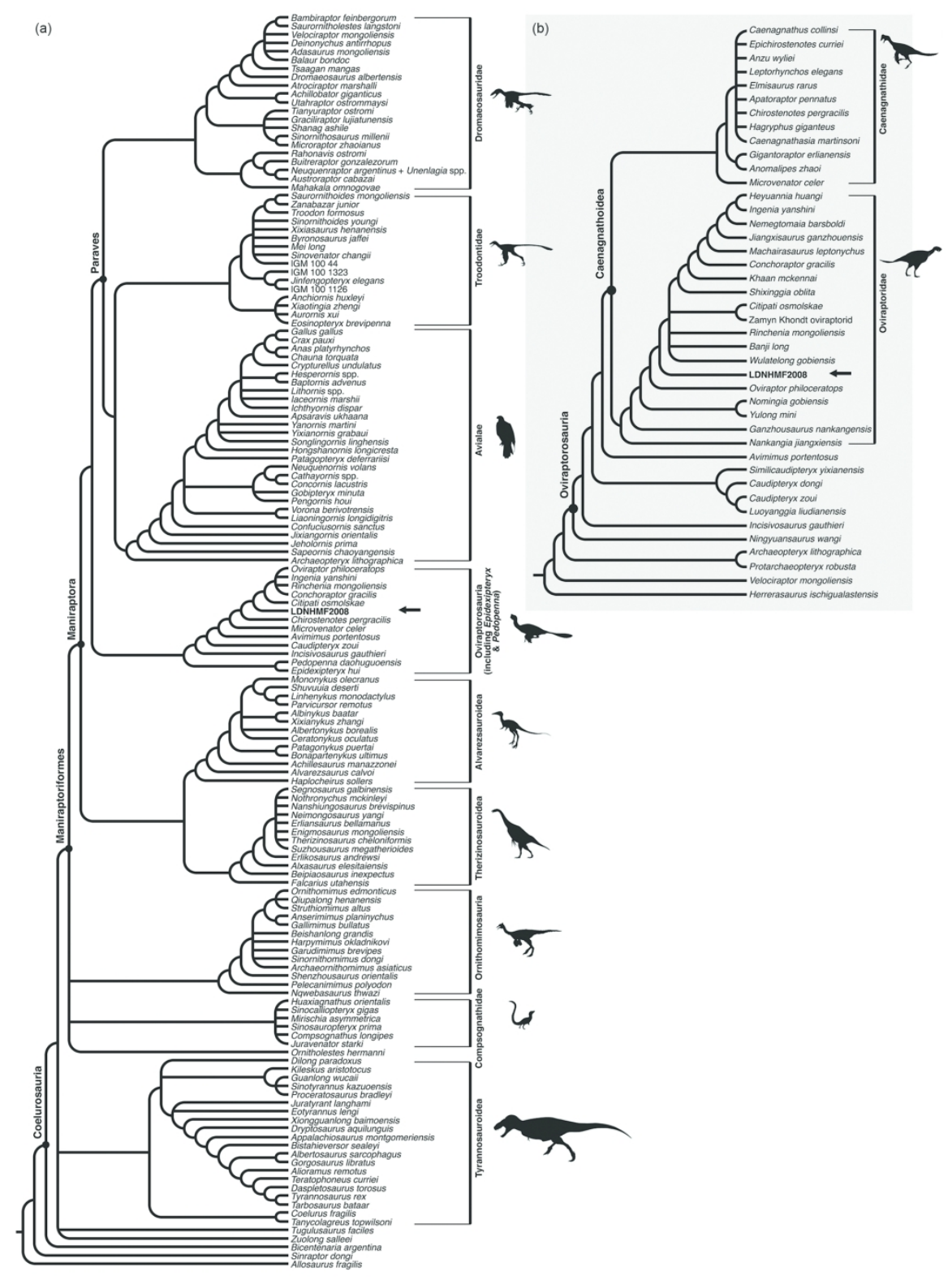

Figure 3

$189 \times 256 \mathrm{~mm}(300 \times 300 \mathrm{DPI})$

www.scibull.com 
(a)
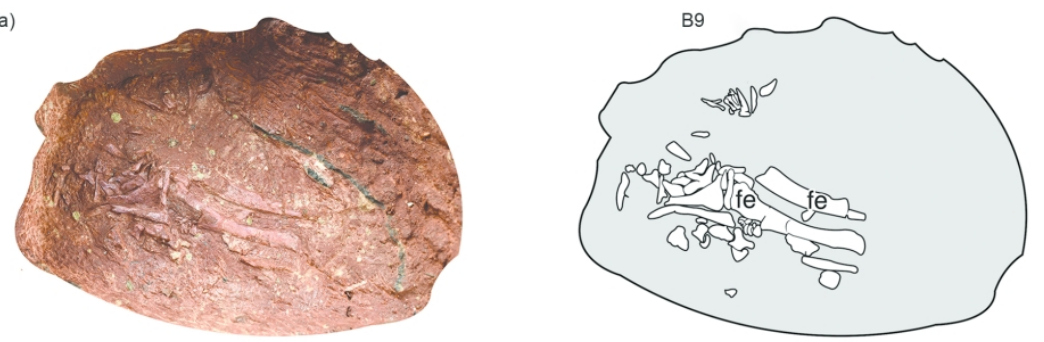

(b)
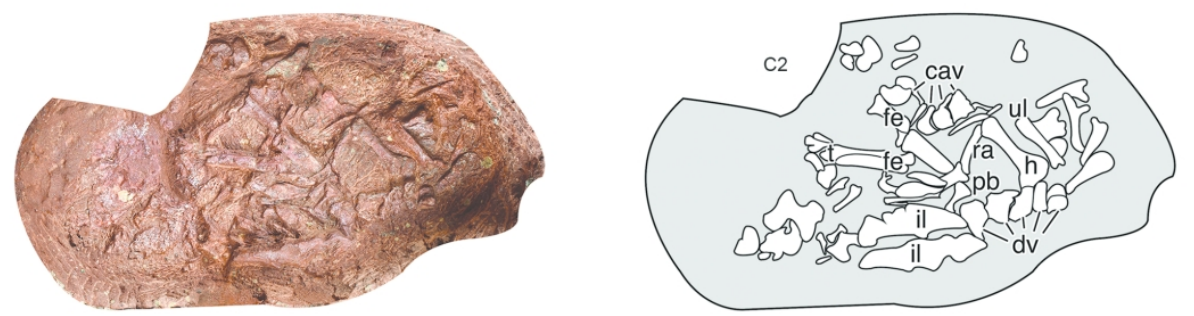

$5 \mathrm{~cm}$

(c)
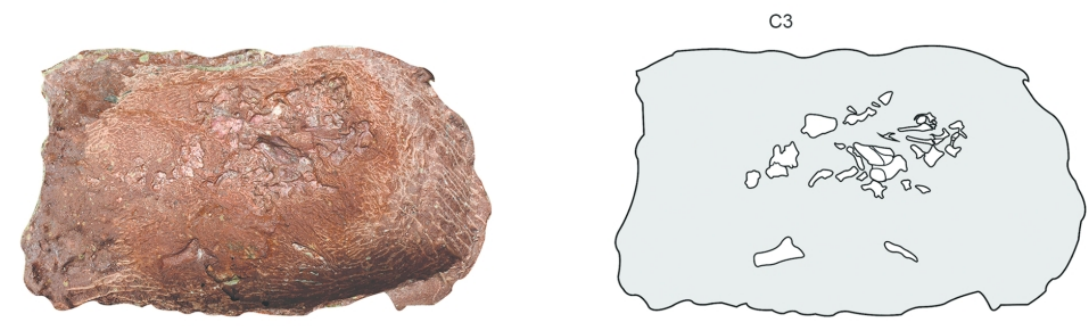

(d)
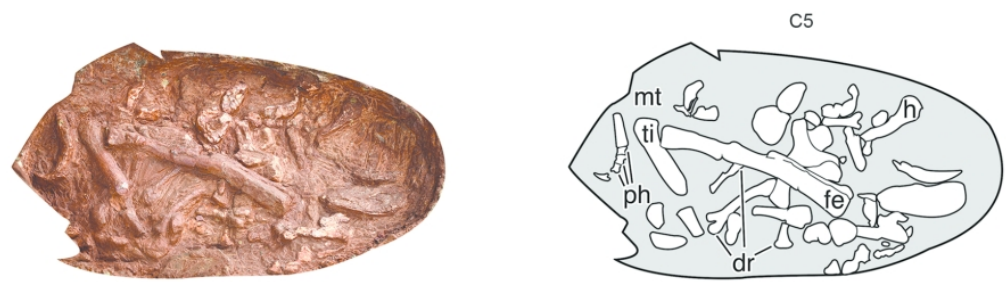

Figure 4

$189 \times 221 \mathrm{~mm}(300 \times 300 \mathrm{DPI})$ 

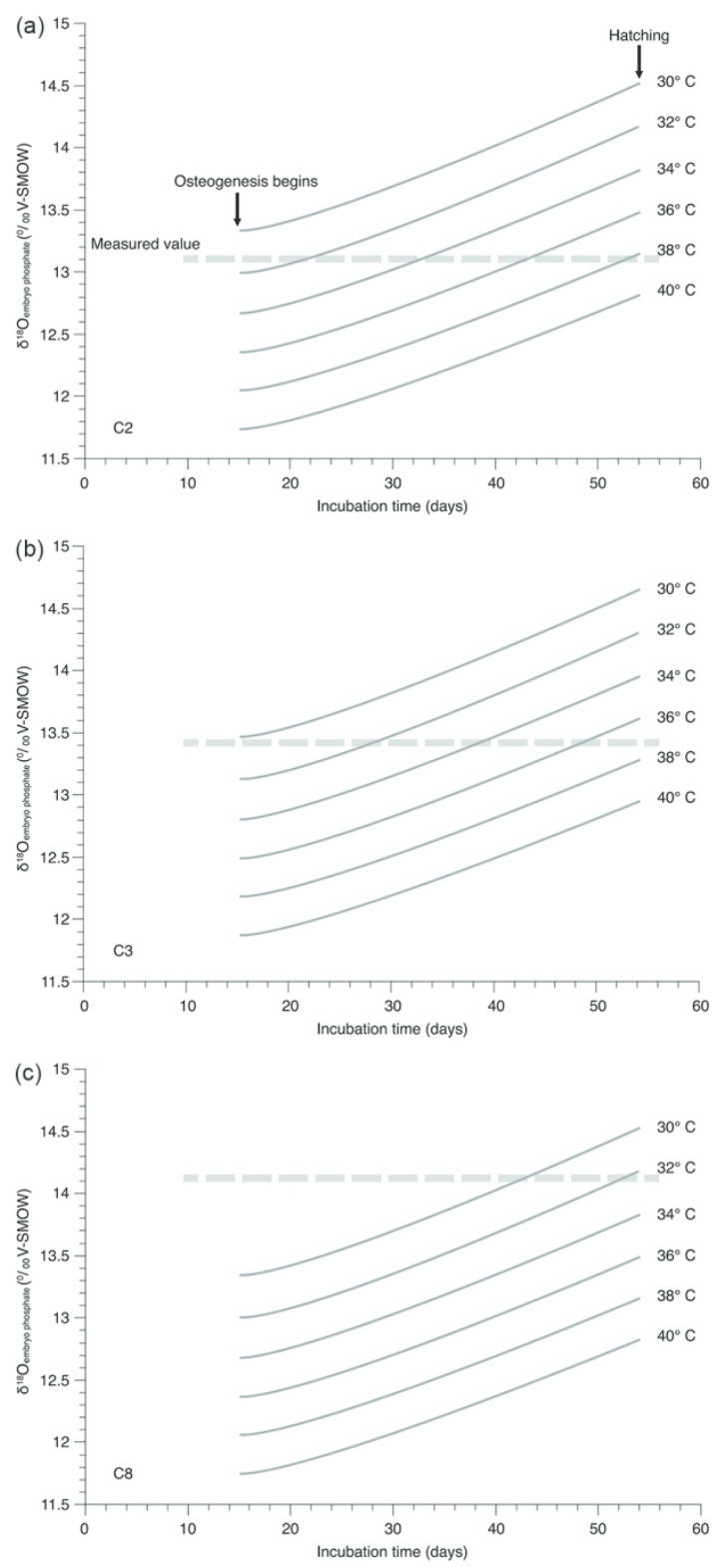

Figure 5

www.scibull.com 


\section{SUPPLEMENTARY MATERIAL}

An oviraptorid preserved atop an embryo-bearing egg clutch sheds light on the reproductive biology of non-avialan theropod dinosaurs

Shundong Bi ${ }^{1,2, *}$, Romain Amiot ${ }^{3}$, Claire Peyre de Fabrègues ${ }^{2}$, Michael Pittman ${ }^{4}$, Matthew C.

Lamanna $^{5}$, Yilun $\mathrm{Yu}^{6}$, Congyu Yu ${ }^{7}$, Tzuruei Yang ${ }^{8,9}$, Shukang Zhang ${ }^{8,9}$, Qi Zhao ${ }^{8,9}$, Xing Xu ${ }^{8,9, *}$

${ }^{1}$ Centre for Vertebrate Evolutionary Biology, Institute of Palaeontology, Yunnan University, Kunming 650091, China.

${ }^{2}$ Department of Biology, Indiana University of Pennsylvania, Indiana, Pennsylvania 15705, USA.

${ }^{3}$ Univ Lyon, Univ Lyon 1, ENSL, CNRS, LGL-TPE, F-69622, Villeurbanne, France.

${ }^{4}$ Department of Earth Sciences, University of Hong Kong, Pokfulam, Hong Kong, China.

${ }^{5}$ Section of Vertebrate Paleontology, Carnegie Museum of Natural History, Pittsburgh, Pennsylvania 15213, USA.

${ }^{6}$ Yuan Pei College, Peking University, Beijing 100871, China.

${ }^{7}$ Division of Paleontology, American Museum of Natural History, New York, NY 10024, USA.

${ }^{8}$ Key Laboratory of Vertebrate Evolution and Human Origins, Institute of Vertebrate Paleontology and Paleoanthropology, Chinese Academy of Sciences, Beijing 100044, China.

${ }^{9} \mathrm{CAS}$ Center for Excellence in Life and Paleoenvironment, Beijing 100044, China.

Part A. Systematic paleontology and supplemental description

Part B. Phylogenetic analysis

Part C. Isotopic analysis

Part D. Institutional abbreviations

Part E. Tables of measurements and results of isotopic analysis

Part F. References 


\title{
Part A. Systematic paleontology and supplemental description
}

\author{
Theropoda Marsh, 1881 \\ Maniraptora Gauthier, 1986 \\ Oviraptorosauria Barsbold, 1976 \\ Oviraptoridae Barsbold, 1976 \\ Genus and species indet.
}

Material. LDNHMF2008 (Lande Museum of Natural History, Tangshan, Hebei Province, China): an articulated partial postcranial skeleton of a large, presumably sexually mature individual preserved atop a clutch of at least 24 eggs. The attending individual is missing the skull, a significant part of the vertebral series, the pectoral girdle, the right humerus, and most of the left humerus. The egg clutch contains at least seven embryonic skeletons (Figs. 1, 2b and 4, Tables S1, S2).

Locality and horizon. Near the Ganzhou railway station, Ganzhou city, Jiangxi Province, China. Upper Cretaceous (Maastrichtian) Nanxiong Formation.

Comments. Specimen LDNHMF2008 is preserved in a red sedimentary matrix that is dominated by brown-red siltstone and silty mudstone with sandstone and conglomerate interbed. The matrix also contains sporadic gravel-sized clasts, including in one of the eggs. The sedimentary environment of the Nanxiong Formation lacks eolian deposit and as a whole was fluviolacustrine [2, 3]. The grain size distribution appears wider than in the red sandstone of the Djadokhta Formation that entombs the nesting oviraptorid (Citipati osmolskae) specimen IGM 100/979, which is thought to have been rapidly buried during a sandstorm [1].

Supplemental description and comparisons: skeleton. The large, attending, presumably adult individual in specimen LDNHMF2008 lacks the skull, part of the cervical series, much of the dorsal and caudal series, the pectoral girdle, the right humerus, and most of the left humerus (Fig. 1). The remaining parts of the skeleton and the clutch appear undisturbed and are preserved in life posture. The pelvic girdle and hind limbs are in near-perfect articulation and are positioned in the centre of the clutch. What remains of the forelimbs are splayed posteriorly and ventrally (Fig. 1a, b).

The cervical centra are amphicoelous and subrectangular in lateral view and bear a pneumatic foramen on the lateral surface. The dorsal centra are anteroposteriorly longer than dorsoventrally high and exhibit emarginated pneumatic fossae and a single pneumatic foramen. These features are observed in most Oviraptorosauria. The anterior caudal vertebrae are short with a pneumatic opening on the lateral surface of the centra, as in many oviraptorosaurs including the Nanxiong Formation oviraptorids Jiangxisaurus ganzhouensis [4] and Tongtianlong limosus [5]. The ventral margin of the 
caudal centra is concave in lateral view. Some fragmentary dorsal ribs and gastralia are preserved in or near the abdominal cavity. A small mass of pebbles situated immediately posterior to the gastralia probably represents gastroliths (Fig. 1a, b ). The gastroliths are rounded and less than $1 \mathrm{~cm}$ in diameter. Their position is consistent with the location of a potential gizzard. Until now, gastroliths had only been reported in Caudipteryx spp. within Oviraptorosauria [6-8]; as such, this is the first occurrence of these 'stomach stones' in a late-diverging oviraptorosaur. The identification of gastroliths in an oviraptorid may hold implications for reconstructing the diets of these theropods.

The adult skeleton preserves much of the left forelimb, including the fragmentary distal end of the humerus, the complete radius and ulna, the carpus, and the manus with the exception of metacarpal I; also, the distalmost two phalanges of digit II (non-ungual phalanx II-2 and ungual II-3) are crushed and partly destroyed (Fig. 1). Preserved elements of the right forelimb include part of the ulna and all manual phalanges, with only the ungual of digit II being incomplete. The forelimb is gracile and the manus is elongate relative to the antebrachium. The distal end of the humerus has a reduced medial epicondyle and a flat and relatively well-developed lateral epicondyle. The left ulna is bowed posteriorly with a weakly developed olecranon process. Its proximal extremity is crescentshaped. The shaft is mediolaterally broad and tapers slightly distally, with a rounded distal end. The radius is slenderer than the ulna, straight, and mediolaterally compressed, and appears to lack the bifurcate distal end seen in the caenagnathid Anzu wyliei [9]. Metacarpal II is longer than metacarpal III, whereas these metacarpals are equal in length in Corythoraptor jacobsi [10], a recently-named crested oviraptorid from the same general locality and horizon (Table S2).

The manual phalangeal formula is 2-3-4 (Fig. 1). Digit I is the shortest of the manus. Digit II is longer than digit III, as in the Nanxiong oviraptorids Huanansaurus ganzhouensis [11] and Jiangxisaurus [4]. In the latter, the ungual of digit III appears less recurved than those of digits I and II, as in LDNHMF2008. Manual phalanx I-1 is shorter than metacarpal II, as in Nemegtomaia barsboldi [12], Heyuannia huangi [13], and Ingenia yanshini [14]. The shaft diameter of phalanx I-1 equals that of the radius. Phalanges II-1 and II-2 are subequal in length and two thirds the length of phalanx I-1. The combined length of phalanges II-1 and II-2 is greater than that of metacarpal II. Phalanges III-1 and III-2 are the smallest manual phalanges, each being roughly half the length of phalanx I-1. Phalanx III-3 is slightly longer than phalanx III-1. The combined length of phalanges III-1 and III-2 is greater than that of phalanx III-3, as in the early-diverging oviraptorosaur Protarchaeopteryx robusta [6]. The collateral ligament pits of the manual non-ungual phalanges are strongly developed. The proximal articular surface of these phalanges is concave, whereas the distal surface is convex. As in other oviraptorosaurs, the manual unguals are dorsoventrally deep and 
laterally compressed and have well-developed flexor tubercles near the proximal end; this is especially true of unguals I and II.

The forelimbs are spread symmetrically around the outer perimeter of the nest, covering the 'anterior' or 'forward' part of the latter. This position almost certainly reflects a natural posture adopted by the animal in life rather than a taphonomic or preservational artefact. Therefore, it provides direct evidence that individuals of this oviraptorid taxon sat on their nests, as is the case in modern birds and other oviraptorids such as Citipati [1, 15] and Nemegtomaia [12].

Both ilia and pubes, the proximal ends of both ischia, and both femora, tibiae, fibulae, and several tarsal and pedal elements are preserved in situ and partially to almost fully exposed (Fig. 1, table S2). Both ilia are well preserved, with only the preacetabular process of the left ilium missing. The ilia are anteroposteriorly elongate and dorsoventrally shallow with a convex dorsal border, as in the indeterminate Nanxiong oviraptorid specimen NMNS-VPDINO-2002-0901 [16]. The dorsoventral height/anteroposterior length ratio of the ilium is low, unlike in the southern Chinese oviraptorids Nankangia [17] and Shixinggia oblita [18], in which this ratio is higher. The preacetabular process of the right ilium projects anteroventrally and its anteroventral corner is rounded, as in Nankangia [17] and Heyuannia, another oviraptorid from southern China [13]. The postacetabular process is slightly shorter and straighter than the preacetabular process, unlike in Shixinggia [18]. The ilium is shorter than the femur (Table S2) as in Nankangia [17] and unlike most other oviraptorids. The pubis is mesopubic. The pubic boot does not appear markedly expanded in lateral view, contrasting what is observed in most other Oviraptorosauria (with rare exceptions, e.g., Anzu; MCL pers. obs.), including the Nanxiong Formation oviraptorids Nankangia [17] and Corythoraptor [10]. The ischium is elongate and slender. The posterior surface is visible only on the left ischium and is smooth. The proximodorsal process of the ischium forms a small tab along the posterior edge of the bone. The ventral margin of the pubic process is flat, lacking the hooked extension present in Anzu [9], Epichirostenotes curriei [19], and Nomingia gobiensis [20]. The distal end of the ischium is not exposed so its morphology cannot be observed.

The femur is robust with a suboval midshaft cross section. The greater trochanter is well separated from the femoral head. It is fused with the lesser trochanter, forming a trochanteric crest, as in most Oviraptorosauria with the exception of Nankangia [17]. The left tibia is straight and about $115 \%$ the length of the femur (Table S2). The tibia is also longer than the femur in Corythoraptor [10] and Tongtianlong [5], whereas in Nankangia these bones are subequal in length [17]. The metatarsus is relatively short, as in another Nanxiong Formation oviraptorid, Ganzhousaurus 
nankangensis [21]. Metatarsals II and III are separate from one another and do not form an arctometatarsus. The proximodistal length of the proximal phalanges of pedal digits II and III is greater than their midshaft width. Pedal phalanx II-2 is as long as pedal phalanx II-1. Pedal ungual III is curved in lateral view and bears a dorsal extensor lip that overhangs the proximal articular surface. The ungual of pedal digit II is similar to that of pedal digit III.

Supplemental description and comparisons: clutch. The clutch consists of at least 24 eggs exposed beneath the adult skeleton (Fig. a, b, table S1). The nest is mostly intact, exhibiting slight or little deformation or compression of the eggs, and preserving paired eggs arranged in three superimposed rings. The number of eggs and their arrangement within the clutch is consistent with what is usually observed in oviraptorid nests; for example, one of the first reports of a nest consisting of three concentric circles of eggs at different heights was made by Brown and Schlaikjer [22: p. 254]. In this case, the lowest egg ring was also the most central, as also occurs in LDNHMF2008. Based on the outer clutch diameter and eggshell thickness, the eggs are referable to the oospecies Macroolithus yaotunensis [23]. The predicted adult body mass for the theropod represented by this ootaxon is $85-196 \mathrm{~kg}$ [24].

Ossified embryonic material is observed in seven eggs, six of which are in ring $\mathrm{C}$; the seventh is in ring B. Specifically, eggs C2, C3, C5, C6, C7, C8, and B9 are known to contain embryonic material.

Supplemental description and comparison: embryonic remains. Well-ossified embryonic material with identified morphology can only be recognized in eggs B9, C2, C3, and C5 (Fig. 4). The skeleton inside egg C2 is probably complete, and a large assemblage of bones has been exposed, including vertebrae, dorsal ribs, a humerus, both ilia and femora, and a tibia (Fig. 4b). The skeleton is semiarticulated and in a generally curled posture, as in other described oviraptorosaurian embryos such as that of Beibeilong sinensis (HGM 41HIII1219) [25]. This closely resembles the in ovo posture of extant crocodilians [26] and birds [27]. The huemerus is nearly complete and fully ossified with fused proximal and distal articular end. Both femora are preserved, one lacks the distal end while the other is crushed.

Egg C3 contains vertebrae, dorsal ribs, and putative pelvic bones (Fig. 4c). Most of the skeleton is localized in one corner of the egg rather than being spread throughout. The remains are not as clearly exposed as are those in egg $\mathrm{C} 2$ or $\mathrm{C} 5$; therefore, no long bones are visible.

Egg C5 has as many bones exposed as in C2 (Fig. 4d). A few vertebrae and limb elements can be identified, the latter including a putative radius and ulna, a femur, a tibia, and potential pedal elements. The femur is in better condition than that in egg C2. It is robust and subcircular in cross 
section. As in the embryo in egg $\mathrm{C} 2$, both extremities of the bone are exposed and ossified. The femur is approximately $5.5 \mathrm{~cm}$ long.

Egg B9 exposes fewer embryonic elements than do the eggs in layer C (Fig. 4a); approximately 12 bones are distinctly visible compared with more than 20 in eggs C2 and C5. Most of the remains are difficult to identify, though among them are a few probable vertebrae and several limb bones. Two long bones-herein identified as femora given their length, robustness, and curvature - are clearly visible at the centre of the egg. These differ from the femora observed in layer $\mathrm{C}$ in that their extremities are not well defined and therefore their epiphyses seem to be incompletely ossified. The better exposed, more complete femur in egg B9 is approximately $4 \mathrm{~cm}$ in length, more than $1 \mathrm{~cm}$ shorter than that in $\mathrm{C} 5$. Based on these observations, we suspect that the embryos in the middle layer of the clutch (layer B) are at an earlier developmental stage than are those in the upper layer (layer C).

Systematic assessment. Within Oviraptorosauria, the adult skeleton of specimen LDNHMF2008 exhibits caenagnathoid affinities in having pneumatic foramina (pleurocoels) on its caudal vertebral centra and an anteriorly concave pubic shaft. Within Caenagnathoidea, the specimen is referred to Oviraptoridae on the basis of the following features: (1) one rather than two pneumatic foramina on lateral surfaces of cervical vertebral centra; (2) pubis with small, shoe-like distal boot in which the anterior process is longer than the posterior process; (3) pubis short relative to ilium; (4) small groove rather than large cleft separating greater and lesser and trochanters of femur; and (5) metatarsal III not proximally compressed. The eggshell structure seen in the specimen is also closely similar to that of other oviraptorosaurian eggs reported from the same general geographic region and stratigraphic unit. Altogether, these observations leave no doubt concerning the phylogenetic affinities of the material within Oviraptoridae.

Nine monotypic oviraptorid species are known from Upper Cretaceous horizons in the neighbouring provinces of Jiangxi and Guangdong in southern China: Banji long [28], Corythoraptor jacobsi [10], Ganzhousaurus nankangensis [21], Heyuannia huangi [13], Huanansaurus ganzhouensis [11], Jiangxisaurus ganzhouensis [4], Nankangia jiangxiensis [17], Shixinggia oblita [18], and Tongtianlong limosus [5]. Most of these are incompletely preserved and some are not fully prepared. The skull is the only osteological region known for Banji [28], preventing comparisons with LDNHMF2008. The eight other genera can theoretically be considered; however, proper comparisons with the holotypes of Ganzhousaurus [21], Huanansaurus [11], Jiangxisaurus [4], Shixinggia [18], and Tongtianlong [5] are precluded given that they have few overlapping elements with LDNHMF2008. For these reasons, LDNHMF2008 cannot be confidently referred to an existing oviraptorid species from the Upper Cretaceous of southern China. 


\section{Part B. Phylogenetic analysis}

To investigate the systematic position of specimen LDNHMF2008, we conducted a phylogenetic analysis based on a recently published coelurosaurian theropod dataset [29]. The matrix includes 853 characters and 151 species, to which we added the specimen described here (see below for the scorings (a) of LDNHMF2008). The matrix was analysed with equally weighted parsimony in Tree analysis using New Technology (TNT) version 1.5 [30] via the "New Technology Search" with default parameters, except for the value "Find min. length" which was changed from one to ten times. 64 most parsimonious trees $(\mathrm{MPTs})$ of 4,655 steps were recovered $($ Consistency Index $[\mathrm{CI}]=$ 0.23 , Retention Index $[\mathrm{RI}]=0.66)$. As the strict consensus tree is poorly resolved, we calculated a reduced consensus following the methodology of the original study [29]. The resulting cladogram is shown in Fig. 3a; therein, LDNHMF2008 is supported as a derived member of Oviraptorosauria.

To further resolve the position of LDNHMF2008 within Oviraptorosauria, we conducted a second phylogenetic analysis. The matrix was based on a modified version of the first dataset published in the recent description of the caenagnathid Anomalipes zhaoi [31]. We added the new specimen and deleted one character (262) (see below for the scorings (b) of LDNHMF2008). The analysis was conducted using the "Traditional search" function of TNT 1.5 [30], with 1,000 random seeds, 1,000 replicates, and the Tree Bisection and Reconnection swapping algorithm (ten trees saved per replication). We obtained $119 \mathrm{MPTs}$ of 670 steps $(\mathrm{CI}=0.46, \mathrm{RI}=0.64)$, the strict consensus of which is shown in Fig. 3b. LDNHMF2008 is positioned within Oviraptorosauria, and more specifically within Oviraptoridae, close to genera such as Banji, Rinchenia, Wulatelong, and the clade that includes Citipati and the unnamed Zamyn Khondt taxon. Oviraptor is recovered as the sister taxon of LDNHMF2008 and other late-diverging oviraptorids.

Scorings (a) based on Brusatte et al. [29]:

LDNHMF2008??????????????????????????????????????????????????????????????????????????

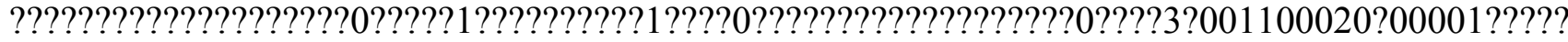
??0????12?1???21?1100???0?????0??00???000???0???????????00??00????0????????????????????0 ?????2???????????????????????????????????????????????0?11???0?????????????????????????????

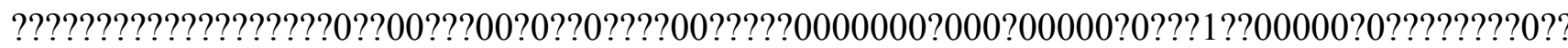
???000????????????????????0????????0??00????????????????????????????????????????????????? ?????????????????????????????????????????????????????????????????????????????????????????? ??????????????????????????????????????????????000??????010?????????00?????2???10000????1 ?010?000?0?000?0?????00???????100??0??0???????????00????00??0?010????????????????0?1???? ???000000000???00??????0?002?0????????0?????1?11??01?????? 
Scorings (b) based on Yu et al. [31]:

LDNHMF2008???????????????????????????????????????????????????????????????????????+?????

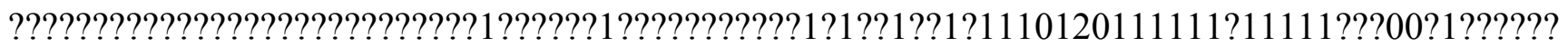

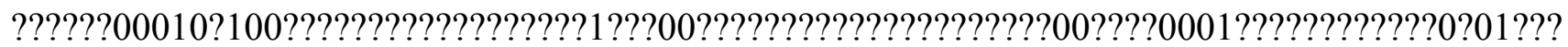
$? 001 ? 1 ? 0$ 


\section{Part C. Isotopic analysis}

Method. A $3 \mathrm{mg}$ aliquot of bone from each analysed embryo of oviraptorosaurian specimen LDNHMF2008 was ground into fine powder using a mortar and pestle. Powder from each sample was treated following the wet chemistry protocol described by Lécuyer [32] and adapted by Bernard et al. [33] for small sample weights $(3 \mathrm{mg})$. This protocol involves a wet chemical isolation of phosphate ions from apatite using acid dissolution followed by an anion-exchange resin separation and subsequent precipitation as Ag3PO4 crystals. For each sample, the $3 \mathrm{mg}$ of bone powder were dissolved in $1 \mathrm{~mL}$ of $2 \mathrm{M} \mathrm{HF}$ overnight. The CaF2 residue was separated by centrifugation and the solution was neutralized by adding $1 \mathrm{~mL}$ of $2 \mathrm{M} \mathrm{KOH}$. About $1.5 \mathrm{~mL}$ of Amberlite ${ }^{\mathrm{TM}}$ anion-exchange resin was added to the solution to separate the PO43- ions. After 24 hours, the solution was removed and the resin was eluted with $6 \mathrm{~mL}$ of $0.1 \mathrm{M} \mathrm{NH} 4 \mathrm{NO} 3$. After 4 hours, $0.1 \mathrm{~mL}$ of NH4OH and $3 \mathrm{~mL}$ of an ammoniacal solution of AgNO3 were added and the samples were placed in a thermostated bath set at $70^{\circ} \mathrm{C}$ for 6 hours allowing the precipitation of $\mathrm{Ag} 3 \mathrm{PO} 4$ crystals. Oxygen isotope compositions were measured using a high-temperature pyrolysis technique involving a VarioPYROcubeTM elemental analyser (EA) interfaced in continuous flow (CF) mode to an IsoprimeTM isotopic ratio mass spectrometer at the Laboratoire de Géologie de Lyon (UMR 5276, Université Claude Bernard Lyon 1). For each sample, 5 aliquots of $300 \mu \mathrm{g}$ of Ag3PO4 were mixed with $300 \mu \mathrm{g}$ of pure graphite powder and loaded in silver foil capsules. Pyrolysis was performed at $1450^{\circ} \mathrm{C}$. Measurements were calibrated against the NBS120c (natural Miocene phosphorite from Florida with a proposed $\delta 18 \mathrm{O}$ of 21.7\% V-SMOW [34]) and the NBS127 (barium sulfate with a certified $\delta 180$ value of 9.3\%o VSMOW. Silver phosphate samples precipitated from standard NBS120c were repeatedly analysed $(\delta 18 \mathrm{Op}=21.7 \pm 0.3 \% \mathrm{n}, \mathrm{n}=2)$ along with the silver phosphate samples derived from fossil bioapatites to ensure that no isotopic fractionation took place during the wet chemistry. The average standard deviation equals $0.3 \pm 0.1 \%$. Data are reported as $\delta 180$ in $\%$ values vs. V-SMOW.

Oviraptorosaur eggshell fragments were cleaned in an ultrasonic bath with distilled water and dried at room temperature. Eggshells were then ground into fine powder in an agate mortar. For each sample, two aliquots of about $500 \mu \mathrm{g}$ were reacted with anhydrous oversaturated phosphoric acid at $90^{\circ} \mathrm{C}$ for 12 minutes and analysed using a MultiPrep ${ }^{\mathrm{TM}}$ automated system coupled to a dual-inlet Elementar Isoprime ${ }^{\mathrm{TM}}$ IRMS at the Laboratoire de Géologie de Lyon (LGL), France. Carbon and oxygen isotope compositions are quoted in the $\delta$ notation in per mil relative to V-PDB (Vienna Pee Dee Belemnite). Calibrated material used for value normalization is Carrara Marble $\left(\delta^{18} \mathrm{O}_{\mathrm{V}-\mathrm{PDB}}=\right.$ $1.84 \%$; $\delta^{13} \mathrm{C}_{\mathrm{V}-\mathrm{PDB}}=+2.03 \%$ [35] and NBS18 $\left(\delta^{18} \mathrm{O}_{\mathrm{V}-\mathrm{PDB}}=-23.2 \% ; \delta^{13} \mathrm{C}_{\mathrm{V}-\mathrm{PDB}}=-5.01 \%\right.$ ) analysed within the same batch. External reproducibility is $\pm 0.1 \%$ for $\delta^{18} \mathrm{O}$ values and $\pm 0.05 \%$ or $\delta^{13} \mathrm{C}$ values 
$(2 \sigma)$. Conversion of $\delta^{18} \mathrm{O}$ values of calcite from V-PDB to V-SMOW was performed using the Friedman \& O’Neil [36] formula: $\delta^{18} \mathrm{O}(\% \mathrm{~V}-\mathrm{SMOW})=\delta^{18} \mathrm{O}(\% \mathrm{~V}-\mathrm{PDB}) * 1.03086+30.86$.

Model. A model of daily incremental deposition of oviraptorosaur embryonic bone, slightly modified from that proposed by Amiot et al. [37], was designed based on the following parameters, considerations, and assumptions. First, we assume that, after laying, the eggs were actively brooded until they hatched. Incubation temperature should therefore remain within a narrow range with limited fluctuations and the resulting oxygen isotope composition of embryo bone phosphate should represent an average of this range. Moreover, due to embryo metabolism, which increases with increasing body mass, egg temperature progressively increased during incubation [38, 39]. Egg mass was estimated from egg dimensions using the relationship proposed by Hoyt [40]:

$\mathrm{M}_{\text {egg }}(\mathrm{g})=0.548 * \mathrm{LB}^{2}$

with L corresponding to the maximum length of the egg and B to its maximum breadth or diameter (both in $\mathrm{cm}$ ). The proportions of egg contents were assumed to be similar to those of extant bird eggs, i.e., eggshell mass corresponds to $11 \%$ of total egg mass, yolk mass corresponds to $32 \%$, and the egg white $57 \%$. Water mass corresponds to $88 \%$ of the white and $49 \%$ of the yolk [41]. Because the attending oviraptorid individual was fossilized along with the egg clutch, its body mass (a factor affecting the eggshell calcite-body water oxygen isotope fractionation; see below) was calculated using a relationship established between the minimum shaft circumference of the femur and the body mass which is, for theropod dinosaurs [42]:

$\operatorname{Mass}(K g)=\left(10^{2.749 \times \log \left(F C \times 2^{0.5}-1.104\right)} / 1000\right)$

with $\mathrm{FC}=$ femoral circumference in $\mathrm{mm}$. The embryo began as a fertilized ovum with an assumed mass of $6.4 \mathrm{mg}$ [43]. Hatchling mass represents about 70\% of egg mass [44]. Total water loss during incubation is assumed to represent about $13 \%$ of egg mass [45]. Loss is principally from water vapor and is linear, an equal amount of water being lost each day [46]. The following fractionation equations have been used to predict the evolution of bone phosphate and egg water $\delta^{18} \mathrm{O}$ values during egg incubation: the phosphate-water-temperature scale proposed by Chang and Blake [47] is used to calculate the oxygen isotope composition of bone phosphate increments:

$1000 \ln \alpha_{\left(\mathrm{PO}_{4}-\mathrm{H}_{2} \mathrm{O}\right)}=14.43( \pm 0.39)^{1000 / T(K)}-26.54( \pm 1.33)$ 
with $\alpha$ being the fractionation factor expressed as:

$$
\alpha_{P_{4}-H_{2} O}=\frac{\left(\delta^{18} O_{p}+1000\right)}{\left(\delta^{18} O_{w}+1000\right)}
$$

and $\delta^{18} \mathrm{O}_{\mathrm{p}}$ and $\delta^{18} \mathrm{O}_{\mathrm{w}}$ being the oxygen isotope composition of embryo bone phosphate and egg water, respectively, and $\mathrm{T}(\mathrm{K})$ the egg temperature. The temperature-dependent liquid-vapor fractionation of water [48] is used to calculate the oxygen isotope composition of the water vapor lost by the egg:

$10^{3} * \ln \alpha_{1-v}=-7.685+6.7123 *\left(10^{3} / \mathrm{T}\right)-1.6664 *\left(10^{6} / \mathrm{T}^{2}\right)+0.35041 *\left(10^{9} / \mathrm{T}^{3}\right)$

with $\mathrm{T}$ the temperature in Kelvin. The daily growth of the embryo was estimated using the relationship proposed by Lee [43] relating the embryo body mass $\mathrm{m}(\mathrm{g})$ at a time $\mathrm{t}$ (days) during the incubation:

$m(t)=M_{\text {body }}\left\{1-\left[1-\left(\frac{m_{0}}{M_{\text {body }}}\right)^{0.25}\right] e^{\frac{-0.25 * p * t}{M_{b o d y}^{0.25}}}\right\}^{\frac{1}{0.25}}$

with $\mathrm{m}_{0}$ being the mass of the fertilized ovum $(6.4 \mathrm{mg})$ and $\mathrm{p}$ the metabolic mass gain parameter calculated for precocial birds $\left(=27.46 \mathrm{~kg}^{1 / 4}\right)$ and assumed to be applicable to theropod dinosaurs [43]. All masses ( $\mathrm{m}, \mathrm{M}_{\text {body }}$ and $\mathrm{m}_{0}$ ) are expressed in $\mathrm{kg}$. From this relationship, the time $\mathrm{t}$ at which the embryo mass reaches the expected hatchling mass is considered as the total incubation time. Because the proportion of skeletal to total body mass in the embryo is not known, the mass of embryonic bone was estimated using the scaling relationship between skeletal mass $(\mathrm{kg})$ and total body mass $(\mathrm{kg})$ established for extant birds [49]:

$\mathrm{M}_{\text {skeleton }}=0.065 * \mathrm{M}_{\mathrm{body}}{ }^{1.071}$

As a first approximation, the ossification process is started at day 15 of incubation, following the model of ostriches [50] that we consider to be extant dinosaur relatives that have a body mass and gross morphology comparable to those of oviraptorosaurs. From day 15 to hatching, egg temperature is linearly raised to reach $+2.5^{\circ} \mathrm{C}$ at the end of incubation to account for the increase in metabolic heat production, as observed in both chickens $\left(+2.3^{\circ} \mathrm{C}\right)$ and ostriches $\left(+2.6^{\circ} \mathrm{C}[38,39]\right)$. 
For each daily step, the oxygen content of skeletal growth increment is calculated from the skeletal mass assuming that $70 \%$ of the bone is bioapatite and $30 \%$ is phosphate, and its $\delta^{18} \mathrm{O}$ value is calculated using the phosphate water temperature scale (3) at the egg temperature. Finally, the daily water oxygen loss by evaporation is subtracted from the egg water oxygen reservoir and the subsequent $\delta^{18} \mathrm{O}$ value of remaining water is calculated using a Rayleigh distillation process, with $\alpha$ being the liquid-vapor fractionation factor at the given temperature $\left(\delta^{18} \mathrm{O}_{\mathrm{w}}\right.$ in Table S3). The model stops when the expected body mass of the hatchling is reached. 


\section{Part D. Institutional abbreviations}

HGM, Henan Geological Museum, China; IGM, Institute of Geology, Mongolia; IVPP, Institute of Vertebrate Paleontology and Paleoanthropology, China; LDNHMF, Lande Museum of Natural History, China; MPC-D, Mongolian Paleontological Center-Dinosaur, Mongolia. 


\section{Part E. Tables of measurements and results of isotopic analysis}

Table S1. Length and width measurements of eggs B3, B4, C1-C3, and C12 of oviraptorid specimen LDNHMF2008.

Measurements in $\mathrm{cm}, *=$ egg compressed.

\begin{tabular}{l|cccccc}
\multicolumn{1}{c}{} & B3 & B4 & C1 & C2 & C3 & C12 \\
\cline { 2 - 7 } Length & 19.9 & 19.9 & 21.2 & 23.8 & 23.4 & 20.5 \\
Width & 8.0 & 7.5 & $10.5^{*}$ & 8.6 & 8.8 & 8.7
\end{tabular}

Table S2. Selected measurements of adult oviraptorid skeleton in LDNHMF2008.

Measurements in $\mathrm{cm}$, all are proximodistal lengths except where noted, III = phalanx of manual digit III, - = unable to measure, $*$ = partially preserved.

\begin{tabular}{lcccccccccc}
\hline & Radius & $\begin{array}{c}\text { III- } \\
\mathbf{1}\end{array}$ & $\begin{array}{c}\text { III- } \\
\mathbf{2}\end{array}$ & $\begin{array}{c}\text { III- } \\
\mathbf{3}\end{array}$ & $\begin{array}{c}\text { III-4 } \\
\text { (ungual) }\end{array}$ & Ilium & Pubis & Femur & Tibia & $\begin{array}{c}\text { Femur } \\
\text { circumference }\end{array}$ \\
\hline Left & 22.4 & 4.4 & 3.5 & 3.8 & $5.8^{*}$ & 30.6 & 24.8 & 31.4 & 36.5 & 12.0 \\
Right & - & 4.7 & 3.7 & 3.8 & 6.5 & $29.7^{*}$ & - & 32.4 & 35.6 & 11.6 \\
\hline
\end{tabular}

Table S3. Results of isotopic analyses.

Three-character letter/number combinations at left (e.g.,C8E) indicate egg layer, egg number within that layer, and whether the sample in question was taken from embryonic bone (B) or eggshell (E). $\mathrm{SD}=$ standard deviation; - = value not applicable.

\begin{tabular}{|c|c|c|c|c|c|c|c|}
\hline \multirow[t]{2}{*}{ Sample } & \multirow[t]{2}{*}{ Material } & \multicolumn{2}{|c|}{$\delta^{13} C(\% \circ$ V-PDB) } & \multicolumn{2}{|c|}{$\delta^{18} \mathbf{O}_{\mathrm{CO} 3}(\% 0$ V-SMOW) } & \multicolumn{2}{|c|}{$\delta^{18} \mathbf{O}_{\mathrm{PO} 4}(\% \mathrm{~V}-\mathrm{SMOW})$} \\
\hline & & average & SD & average & SD & average & SD \\
\hline $\mathrm{C} 8 \mathrm{E}$ & eggshell & -8.68 & 0.00 & 21.89 & 0.01 & - & - \\
\hline $\mathrm{A} 2 \mathrm{E}$ & eggshell & -8.78 & 0.00 & 21.12 & 0.06 & - & - \\
\hline $\mathrm{B} 2 \mathrm{E}$ & eggshell & -8.81 & 0.01 & 21.82 & 0.01 & - & - \\
\hline $\mathrm{C} 3 \mathrm{E}$ & eggshell & -8.95 & 0.02 & 22.05 & 0.08 & - & - \\
\hline $\mathrm{C} 2 \mathrm{E}$ & eggshell & -8.44 & 0.01 & 22.15 & 0.01 & - & - \\
\hline $\mathrm{C} 2 \mathrm{~B}$ & embryo femur & - & - & - & - & 13.1 & 0.2 \\
\hline $\mathrm{C} 3 \mathrm{~B}$ & embryo vertebra & - & - & - & - & 13.4 & 0.1 \\
\hline $\mathrm{C} 8 \mathrm{~B}$ & embryo metatarsal & - & - & - & - & 14.1 & 0.2 \\
\hline
\end{tabular}




\section{Part F. References for Supplementary material}

[1] Clark JM, Norell MA, Chiappe LM. An oviraptorid skeleton from the Late Cretaceous of Ukhaa Tolgod, Mongolia, preserved in an avianlike brooding position over an oviraptorid nest. Am Mus Novit 1999;3265:1-36.

[2] Lucas SG, Estep JW. Vertebrate biostratigraphy and biochronology of the Cretaceous of China. N M Mus Nat Hist Sci Bull 1998;14:1-20.

[3] Yan Y, Xia B, Lin G, et al. Geochemistry of the sedimentary rocks from the Nanxiong Basin, South China and implications for provenance, paleoenvironment and paleoclimate at the $\mathrm{K} / \mathrm{T}$ boundary. Sediment Geol 2007;197:127-140.

[4] Wei XF, Pu HY, Xu L, et al. A new oviraptorid dinosaur (Theropoda: Oviraptorosauria) from the Late Cretaceous of Jiangxi Province, Southern China. Acta Geol Sin 2013;87:899-904.

[5] Lü JC, Chen R, Brusatte SL, et al. A Late Cretaceous diversification of Asian oviraptorid dinosaurs: evidence from a new species preserved in an unusual posture. Sci Rep 2016;6:35780.

[6] Ji Q, Currie PJ, Norell MA, S. Ji S. Two feathered dinosaurs from northeastern China. Nature 1998;393:753-761.

[7] Zhou Z, Wang X, Zhang F, Xu X. Important features of Caudipteryx - evidence from two nearly complete new specimens. Vert PalAsiat 2000;38:241-254.

[8] Zhou Z, Wang X. A new species of Caudipteryx from the Yixian Formation of Liaoning, Northeast China. Vert PalAsiat 2000;38:111-127.

[9] Lamanna MC, Sues H-D, Schachner ER, Lyson TR. A new large-bodied oviraptorosaurian theropod dinosaur from the Latest Cretaceous of Western North America. PLos One 2014;9:e92022. [10] Lü J, Li G, Kundrát M, et al. High diversity of the Ganzhou oviraptorid fauna increased by a new “cassowary-like” crested species. Sci Rep 2017;7:6393.

[11] Lü J, Pu H, Kobayashi Y, et al. A new oviraptorid dinosaur (Dinosauria: Oviraptorosauria) from the Late Cretaceous of Southern China and its paleobiogeographical implications. Sci Rep 2015;5:11490.

[12] Fanti F, Currie PJ, Badamgarav D. New specimens of Nemegtomaia from the Baruungoyot and Nemegt formations (Late Cretaceous) of Mongolia. PLos One 2012;7:e31330.

[13] Lü J. A new oviraptorosaurid (Theropoda: Oviraptorosauria) from the Late Cretaceous of southern China. J Vertebr Paleontol 2002;22:871-875. 
[14] Barsbold R. Toothless dinosaurs of Mongolia. Trudy 1981;15:28-39.

[15] Norell MA, Balanoff AM, Barta DE, Erickson GM. A second specimen of Citipati osmolskae associated with a nest of eggs from Ukhaa Tolgod, Omnogov Aimag, Mongolia. Am Mus Novit 2018;3899:1-45.

[16] Deeming DC, Reynolds SJ. Nests, eggs, and incubation: new ideas about avian reproduction. Oxford: Oxford University Press; 2015.

[17] Lü J, Yi L, Zhong H, Wei X. A new oviraptorosaur (Dinosauria: Oviraptorosauria) from the Late Cretaceous of Southern China and its paleoecological implications. PLos One 2013;8:e80557.

[18] Lü J, Zhang B. A new oviraptorid (Theropoda: Oviraptorosauria) from the Upper Cretaceous of the Nanxiong Basin, Guangdong Province of southern China. Acta Palaeontol Sin 2005;44:412-422.

[19] Sues H-D. On Chirostenotes, a Late Cretaceous oviraptorosaur (Dinosauria: Theropoda) from western North America. J Vertebr Paleontol 1997;17:698-716.

[20] Barsbold R, Osmólska H, Watabe M, et al. A new oviraptorosaur [Dinosauria, Theropoda] from Mongolia: the first dinosaur with a pygostyle. Acta Palaeontol Pol 2000;45:97-106.

[21] Wang S, Sun C, Sullivan C, Xu X. A new oviraptorid (Dinosauria: Theropoda) from the Upper Cretaceous of southern China. Zootaxa 2013;3640:242.

[22] Brown DB, Schlaikjer DEM. The structure and relationships of Protoceratops. Tr N Y Acad Sci 1940;2:99-100.

[23] Zhao Z. The microstructure of the dinosaurian eggshells of Nanxiong, Guangdong Province-on the classification of dinosaur eggs. Vert PalAsiat 1975;13:105-117.

[24] Tanaka K, Zelenitsky DK, Lü J, et al. Incubation behaviours of oviraptorosaur dinosaurs in relation to body size. Biol Lett 2018;14:20180135.

[25] Pu H, Zelenitsky DK, Lü J, et al. Perinate and eggs of a giant caenagnathid dinosaur from the Late Cretaceous of central China. Nat Comm 2017;8:14952.

[26] Ferguson MW. Biology of the Reptilia. Hoboken: Wiley and Sons; 1985.

[27] Bellairs R, Osmond M. Atlas of chick development. Cambridge: Academic Press; 2014.

[28] Xu X, Han F. A new oviraptorid dinosaur (Theropoda: Oviraptorosauria) from the Upper Cretaceous of China. Vert PalAsiat 2010;48:11-18.

[29] Brusatte SL, Lloyd GT, Wang SC, Norell MA. Gradual assembly of avian body plan culminated in rapid rates of evolution across the dinosaur-bird transition. Curr Biol 2014;24:2386-2392. 
[30] Goloboff PA, Catalano SA. TNT version 1.5, including a full implementation of phylogenetic morphometrics. Cladistics 2016;32:221-238.

[31] Yu Y, Wang K, Chen S, et al. A new caenagnathid dinosaur from the Upper Cretaceous Wangshi Group of Shandong, China, with comments on size variation among oviraptorosaurs. Sci Rep 2018;8:5030.

[32] Lécuyer C. Oxygen isotope analysis of phosphate. In: de Groot PA, editor. Handbook of Stable Isotope Analytical Techniques. Elsevier; 2004, p. 482-496.

[33] Bernard A, Daux V, Lécuyer C, et al. Pleistocene seasonal temperature variations recorded in the $\delta^{18} \mathrm{O}$ of Bison priscus teeth. Earth Planet Sci Lett 2009;283:133-143.

[34] Lécuyer C, Grandjean P, O’Neil JR, et al. Thermal excursions in the ocean at the CretaceousTertiary boundary (northern Morocco): $\delta^{18} \mathrm{O}$ record of phosphatic fish debris. Palaeogeogr Palaeoclimatol Palaeoecol 1993;105:235-243.

[35] Fourel F, Martineau F, Tóth EE, et al. Carbon and oxygen isotope variability among foraminifera and ostracod carbonated shells. Ann. Univ. Mariae Curie-Sklodowska Sect AAA-Physica 2016;70:133-156.

[36] Friedman I, O’Neil JR. Compilation of stable isotope fractionation factors of geochemical interest (USGS Numbered Series No. 440- KK). Washington: US Government Printing Office; 1977. [37] Amiot R, Wang X, Wang S, et al. $\delta 180$-derived incubation temperatures of oviraptorosaur eggs. Palaeontology 2017;60:633-647.

[38] Ar A. Roles of water in avian eggs. In: Deeming DC, Ferguson MWJ, editors. Egg incubation: its effects on embryonic development in birds and reptiles. Cambridge: Cambridge University Press; 1991, p. 229-243.

[39] Swart D, Rahn H. Microclimate of ostrich nests: measurements of egg temperature and nest humidity using egg hygrometers. J Comp Physiol B 1988;157:845-853.

[40] Hoyt DF. Practical methods of estimating volume and fresh weight of bird eggs. Auk 1979;96:73-77.

[41] Romanoff AL, Romanoff AJ. The avian egg. New York: John Wiley \& Sons; 1949.

[42] Benson RBJ, Hunt G, Carrano MT, Campione N. Cope's rule and the adaptive landscape of dinosaur body size evolution. Palaeontology 2018;61:13-48.

[43] Lee SA. Incubation times of dinosaur eggs via embryonic metabolism. Phys Rev E 2016;94:022402. 
[44] Deeming DC, Birchard GF. Allometry of egg and hatchling mass in birds and reptiles: roles of developmental maturity, eggshell structure and phylogeny. J Zool 2007;271:78-87.

[45] Şahan Ü, Altan Ö, Ipek A, Yilmaz B. Effects of some egg characteristics on the mass loss and hatchability of ostrich (Struthio camelus) eggs. Br Poult Sci 2003;44:380-385.

[46] Smart IHM. Egg shape in birds. In: Deeming DC, Ferguson MWJ, editors. Egg incubation: its effects on embryonic development in birds and reptiles. Cambridge: Cambridge University Press; 1991, p. 101-116.

[47] Chang SJ, Blake RE. Precise calibration of equilibrium oxygen isotope fractionations between dissolved phosphate and water from 3 to $37^{\circ} \mathrm{C}$. Geochim Cosmochim Acta 2015;150:314-329.

[48] Horita J, Wesolowski DJ. Liquid-vapor fractionation of oxygen and hydrogen isotopes of water from the freezing to the critical temperature. Geochim Cosmochim Acta 1994;58:3425-3437.

[49] Prange HD, Anderson JF, Rahn H. 1979. Scaling of skeletal mass to body mass in birds and mammals. Am Nat 1979;113:103-122.

[50] Maxwell EE. Comparative ossification and development of the skull in palaeognathous birds (Aves: Palaeognathae). Zool J Linn Soc 2009;156:184-200. 